\title{
Effect of Experimental Surgery on Mandibular Growth in Syrian Hamsters
}

\author{
W. A. CASTELLI, P. C. RAMIREZ, and A. R. BURDI \\ Department of Anatomy and Center for Human Growth and Development, University of \\ Michigan, Ann Arbor, Michigan 48104, USA
}

Enucleation of the incisor germinal center and extraction of molars in the mandibles of young hamsters produced a significant decrease in the size of the mandibular body, loss of normal occlusion, and a shift of the mandibular body medially and cranially. Condylectomies mainly affected the length of the mandible and were closely related to loss of the articular cartilage and impairment of ramal growth.

Postnatal mandibular growth ${ }^{1,2}$ can be impaired by abnormal development of the mandibular condyle, ${ }^{3}$ ankylosis of the temporomandibular joint,, 45 and by several pathologic complications ${ }^{6-9}$ that are often treated by partial mandibular resection with loss of teeth or tooth germs. However, the effects of mandibular surgery on the growth and functional morphology of the mandible still lack adequate explanation in surgical literature.

This study is concerned with the effects of each of the following on mandibular growth: unilateral condylectomies of the mandible, enucleation of the incisor germinal center, and extraction of molars. Additional attention is given to a comparison of the traumatizing effects of each of the three surgical procedures.

\section{Material and Methods}

Thirty-six 3-week-old Syrian hamsters were placed into two experimental groups of 13 hamsters each and one control group of 10 hamsters. Right condylectomies were performed in one experimental series by making a vertical skin incision immediately

This study was supported by USPHS Grant 02272 and Grant 1433 from Faculty Research, Horace H. Rackham School of Graduate Studies, University of Michigan, Ann Arbor, Mich.

Received for publication December 26, 1969. anterior to the external acoustic meatus, displacing the parotid gland laterally, exposing the outer surface of the masseter muscle, and separating the masseter fibers that cover the region of the temperomandibular joint. Ultimate fracturing of the condylar neck was done by use of a thin, bent hemostat; all condyles were removed after fracture.

In the second experimental series, enucleation of the right incisor germinal center and extraction of all right mandibular molars were done by use of an extraoral approach. The lateral surface of the body of the mandible was exposed through an incision made parallel to the mandibular base. With surgical burs, the incisor germinal center was located in the bone below the molar region. Actual enucleation was accomplished by use of small dental and surgical curettes. Hemorrhage was controlled by packing the cavity with sterile cotton pellets. After each enucleation procedure, an intraoral approach was used for the extraction of the three molars and removal of the incisor crown.

Sham operations, which consisted of the same surgical sequences followed for condylectomy and enucleation procedures, were performed on the left side in hamsters whose right condyles were resected and right incisors enucleated. These sham operations did not break through the mandibular body but were deep enough to reach it.

After six postoperative months, all hamsters were killed and decapitated. Each head was carefully macerated in a steam cooker in preparation for direct measurements. All measurements were made with calipers, read to the nearest tenth of a millimeter, and verified; double-blind determinations were performed for accuracy. 
TABLE 1

MaNdibular MEASUREMENTS

\begin{tabular}{|c|c|}
\hline Variables & Description \\
\hline Length & $\begin{array}{l}\text { (1) Condylion-infradentale (C-G) (enucleation } \\
\text { and control series); } \\
\text { (2) Supraangular notch-infradentale }(N-G) \\
\text { (condylectomy and control series) }\end{array}$ \\
\hline Ramus width & $\begin{array}{l}\text { Measure taken at most convex point of borders } \\
\text { of coronoid process and angle }(P-O) \text { (surgical } \\
\text { and control series) }\end{array}$ \\
\hline Body height & $\begin{array}{l}\text { Alveolar ridge-basilar border }(Z-O) \text { (surgical } \\
\text { and control series) }\end{array}$ \\
\hline Medial shift of mandible & $\begin{array}{l}\text { Gonion-tympanic bulla }(G-B) \quad \text { (surgical and } \\
\text { control series) }\end{array}$ \\
\hline Intermandibular distance & $\begin{array}{l}\text { Distance between right and left antegonial notch } \\
(I-M) \text { (surgical and control series) }\end{array}$ \\
\hline $\begin{array}{l}\text { Alveolar height } \\
\text { increment (maxilla) }\end{array}$ & $\begin{array}{l}\text { Distance from base of orbit to molar occlusal } \\
\text { plane }(O-M) \text { (enucleation and control series) }\end{array}$ \\
\hline
\end{tabular}

The six variables studied and their descriptions are listed in Table 1 and shown in Figure 1.

In experimental and control groups, $t$ tests for difference of means were computed for the six variables of the deeply exposed mandibles and the sham-operated hemimandibles. Those dimensions that varied significantly in both experimental series were also $t$-tested against corresponding measurements in the control contralateral hemimandibles.

\section{Results}

Gross examination of the specimens revealed a substantial morphologic and spatial alteration of the experimental hemimandibles in the enucleation series. Primary observations were a decrease in size of the mandibular body, a loss of normal occlusion, and a shift of the mandibular body medially and cranially. No noticeable changes in occlusion were present in the hamsters with resected right mandibular condyles. Regeneration of a pseudo-condyle, of limited extent, was oberved in the specimens (Figs 2, 3).

ENUCLEATION SERIES.-Since no incisor reappeared after surgery, enucleation of right incisor germinal centers in all hamsters was considered complete. Enucleation did not alter either the width of the ramus or the length of the mandible. This operation, however, was responsible for significant changes $(P=0.01)$ in body height and medial shifting of the experimental hemimandibles (Table 2, Fig 2).

CONDYLECTOMY SERIES.-Condylectomy appeared to alter little of the typical mandibular shape. Similarly, there was little change in the spatial position of the growing, operated-on hemimandible. In this series, mandibular length was the only variable modified significantly (Table 3, Fig 3). Experimental sides were shorter $(P=0.01)$ than the sham-operated sides.

EXPERIMENTAL AND CONTROL HAMSTER COMPARISONS.-Ten control hamsters were used for testing variables that were significantly modified either by condylectomy or by enucleation-extraction procedures. Left hemimandibles of control hamsters were measured. These corresponded to the sham sides in the two surgical series. As expected by the statistical analysis of these comparisons (Table 4 ), there was a highly significant difference $(\boldsymbol{P}=0.01)$ for medial shift and body height when the hemimandibles of the enucleated series were tested against the control contralateral sides.

Statistical analyses of the length of the experimental hemimandibles in the condylectomy series and control contralateral sides (Table 4) gave a highly significant difference as well $(P=0.01)$.

The distance between the right and left mandibular bodies also was reduced significantly as a result of the enucleationextraction procedure (Table 4).

\section{Discussion}

Although incisors constitute a great part of the mandibular body in hamsters, the amount of tissue lost because of the enucleation procedure was limited solely to the incisor germinal center and the bone that 

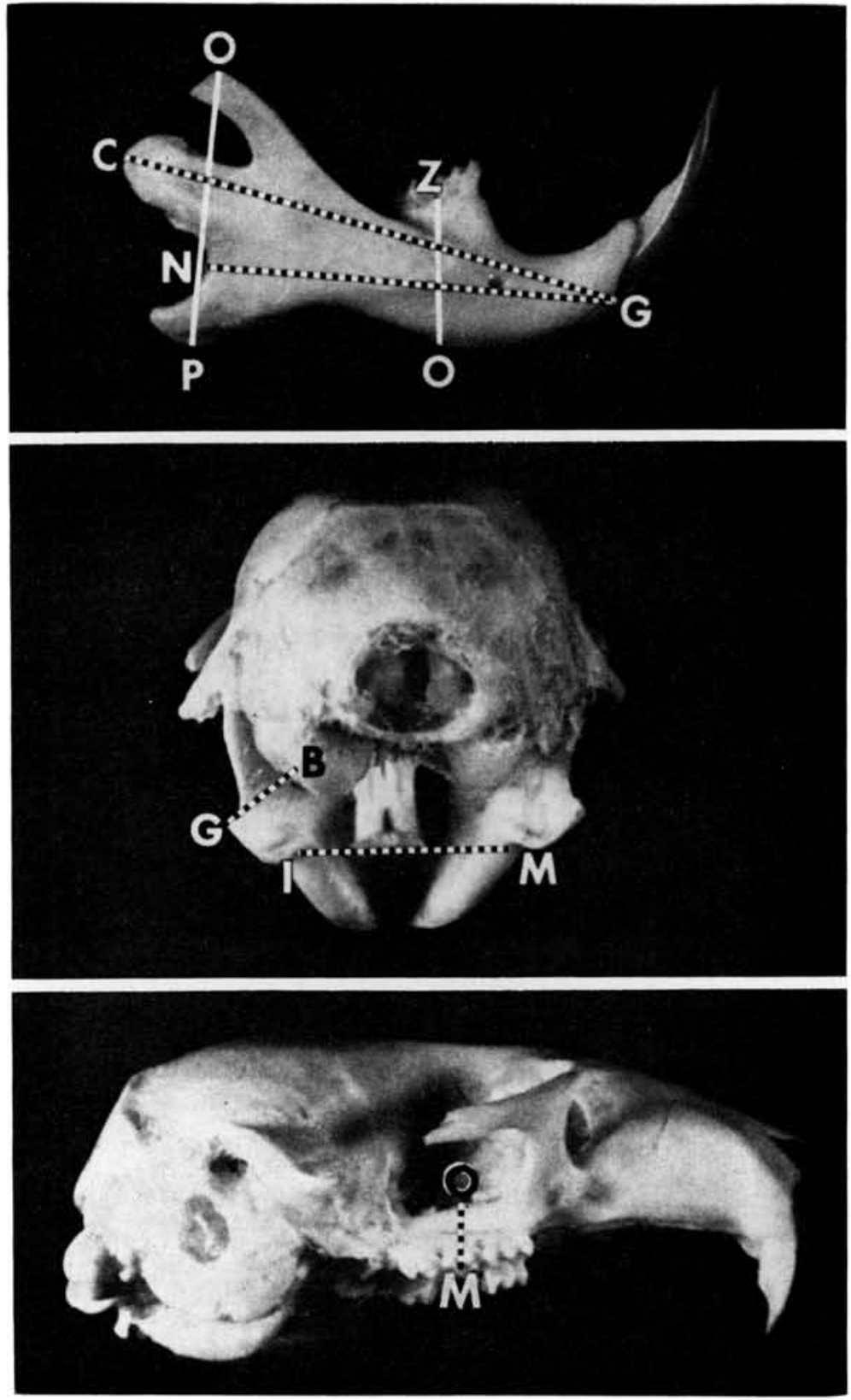

FIG 1,-Linear measurements (Table 1) used in study.

covered it. The main bulk of the tooth. Iying anterior to the extirpated germinal center, remained intact in the body of the mandible.

The most pronounced morphologic changes were obtained in the mandibles as a result of the enucleation-extraction procedure. At least three factors seemed to contribute to this morphologic distortion: (1) the extraction of teeth, which produced resorption of the alveolar cortex and loss of vertical dimension and normal occlu- 

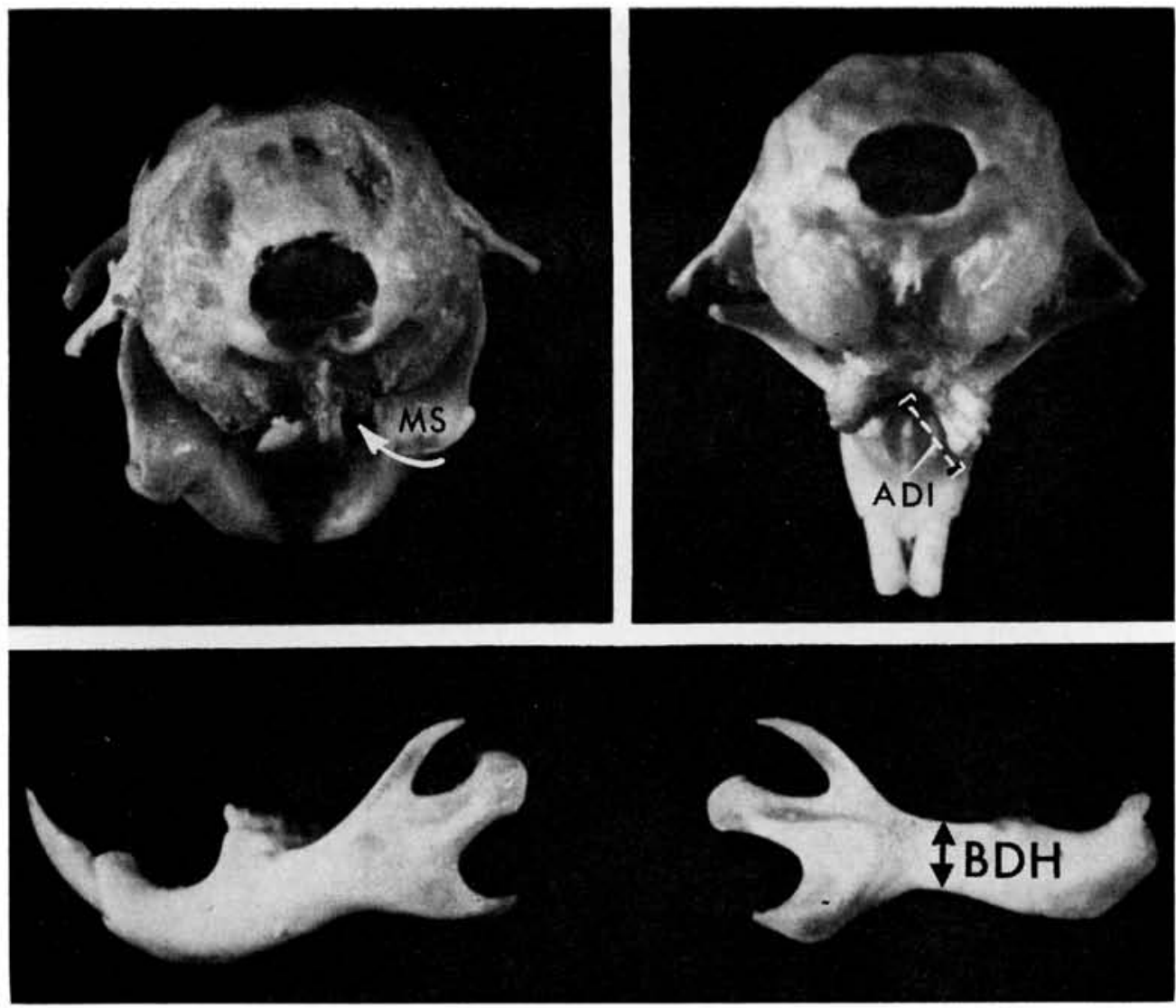

FIg 2.-Macerated skulls show deep morphologic alterations as result of enucleation-extraction procedure. Medial shifting of operated hemimandible $(M S)$ allowed a significant decrease in gonion-bulla distance of same side. $A D I$, maxillary alveolodental increment; $B D H$, decrease in body height.

TABLE 2

Comparison of Experimental and Sham Hemimandibles in the Enucleation Series

\begin{tabular}{|c|c|c|c|c|c|c|c|}
\hline \multirow[b]{2}{*}{ Variables } & \multicolumn{2}{|c|}{$\begin{array}{c}\text { Experimental } \\
\text { Hemimandible }(\mathrm{mm}) \\
(\mathrm{N}=13)\end{array}$} & \multicolumn{2}{|c|}{$\begin{array}{c}\text { Sham } \\
\text { Hemimandible }(\mathrm{mm}) \\
(\mathrm{N}=13)\end{array}$} & \multirow{2}{*}{$\begin{array}{c}\text { Mean } \\
\text { Difference } \\
(\mathrm{mm})\end{array}$} & \multirow[b]{2}{*}{$t$} & \multirow{2}{*}{$\begin{array}{c}\text { Level of } \\
\text { Confidence }\end{array}$} \\
\hline & Mean & SD* & Mean & SD & & & \\
\hline Mandibular length & 21.01 & 0.78 & 21.56 & 0.68 & 0.55 & 1.98 & 0.05 \\
\hline Ramus width & 10.40 & 1.09 & 10.67 & 0.88 & 0.27 & 0.70 & \\
\hline Mandibular body height & 5.07 & 0.33 & 6.77 & 0.20 & 1.70 & 16.661 & 0.01 \\
\hline Medial shift of mandible & 2.38 & 0.56 & 3.99 & 0.15 & 1.61 & 10.25 & 0.01 \\
\hline Alveolodental height & 3.30 & 0.45 & 3.17 & 0.27 & 0.13 & 0.86 & $\ldots$ \\
\hline
\end{tabular}

* SD, standard deviation.

TABLE 3

Comparison of Experimental and Sham Hemimandibles in the Condylectomy Series

\begin{tabular}{|c|c|c|c|c|c|c|c|}
\hline \multirow[b]{2}{*}{ Variables } & \multicolumn{2}{|c|}{$\begin{array}{c}\text { Experimental } \\
\text { Hemimandible }(\mathrm{mm}) \\
(\mathrm{N}=13)\end{array}$} & \multicolumn{2}{|c|}{$\begin{array}{c}\text { Sham } \\
\text { Hemimandible }(\mathrm{mm}) \\
(\mathrm{N}=13) \\
\end{array}$} & \multirow{2}{*}{$\begin{array}{c}\text { Mean } \\
\text { Difference } \\
(\mathrm{mm})\end{array}$} & \multirow[b]{2}{*}{$t$} & \multirow{2}{*}{$\begin{array}{c}\text { Level of } \\
\text { Confidence }\end{array}$} \\
\hline & Mean & SD* & Mean & SD & & & \\
\hline Mandibular length & 16.43 & 0.46 & 17.01 & 0.49 & 0.58 & 3.23 & 0.01 \\
\hline Ramus width & 11.01 & 0.74 & 10.77 & 0.98 & 0.24 & 0.68 & $\ldots$ \\
\hline Medial shift of mandible & 3.80 & 0.51 & 3.98 & 0.49 & 0.18 & 0.88 & $\ldots$ \\
\hline
\end{tabular}

* SD, standard deviation. 

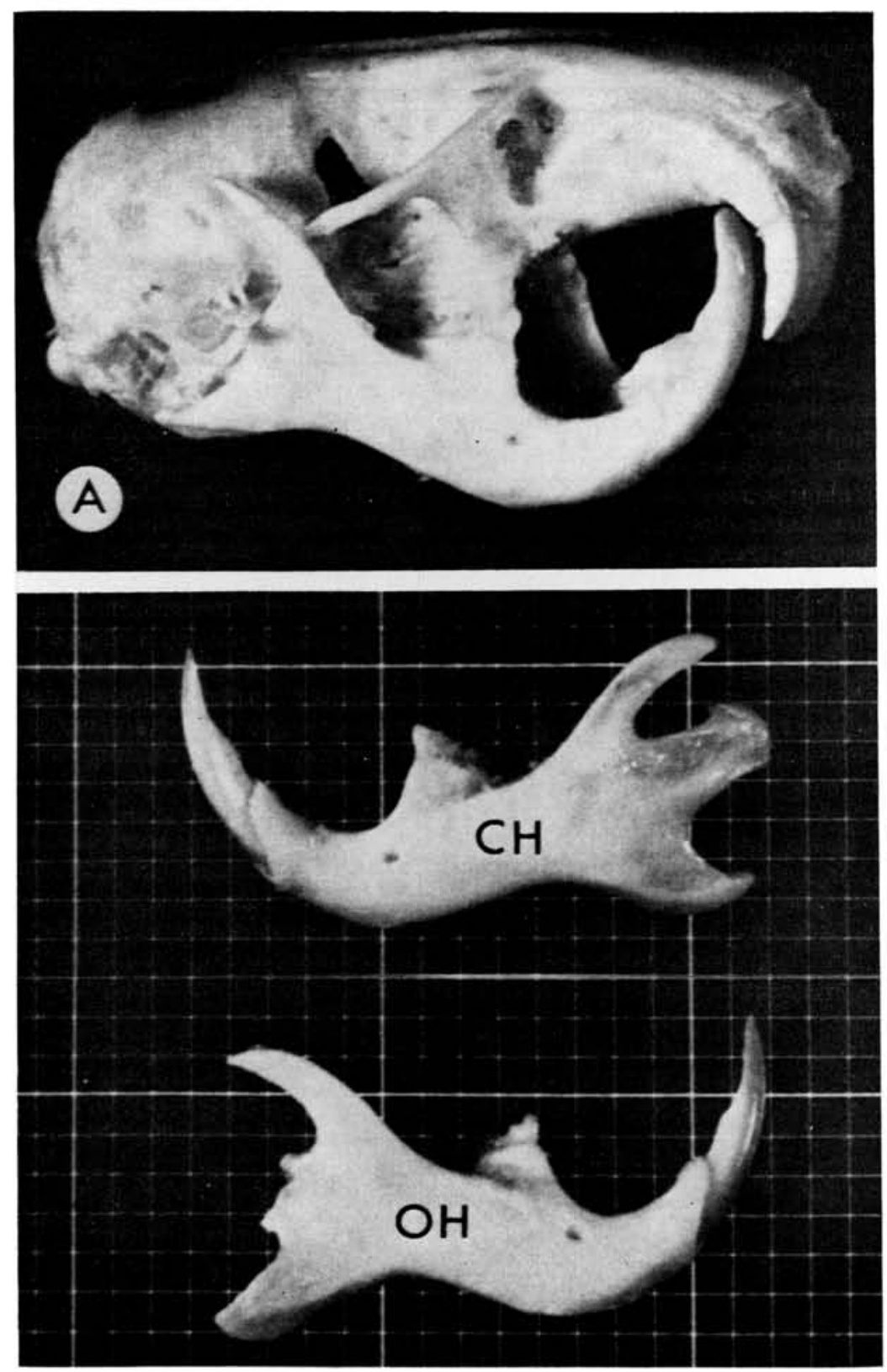

FIG 3.-Condylectomy provoked significant decrease in mandibular length as seen in operated on $(\mathrm{OH})$ and control hemimandible $(\mathrm{CH})$. Skull in $A$ shows normal occlusion and vertical dimension patterns.

$\operatorname{sion}^{10}$; (2) the enucleation of the incisor germinal center, which left a large space in the mandibular body that filled with a slowly organizing blood clot; and (3) the loss of the inferior mandibular artery, the main vascular supply of the mandibular body.

In another project in this laboratory, six hamster heads were injected with different dyes for vascular studies. They showed that 


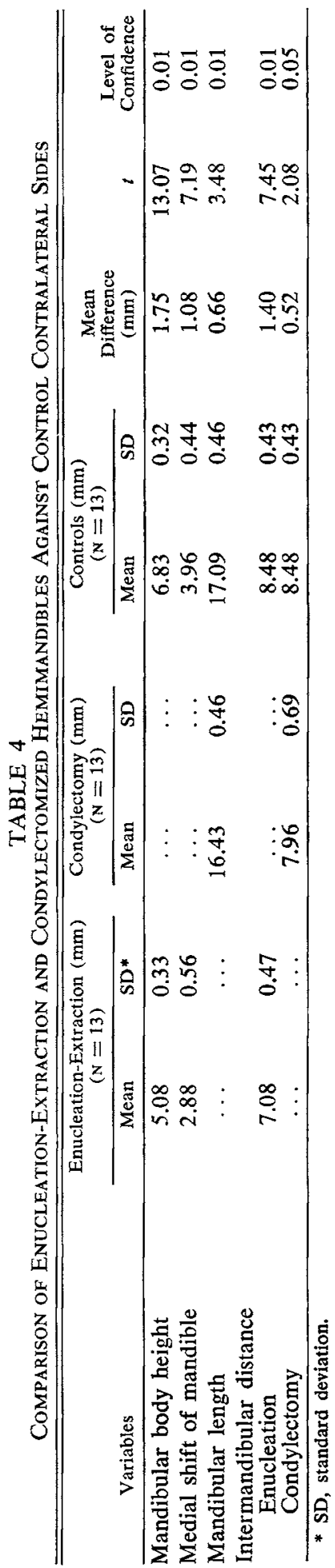

the arterial supply to the mandible was regional in distribution and, in this sense, comparable to that of humans, ${ }^{11}$ Rhesus monkeys, ${ }^{12}$ rats, ${ }^{13}$ and guinea pigs. ${ }^{14}$ There was no evidence of an effective collateral circulation that would take over the nutrition of the bone where the enucleation was performed. Consequently, the nutrition of the region was temporarily mediated by the organizing blood clot through a process that has been called serum imbibition. ${ }^{15}$ With bone substrates, however, this type of nutrition has to be limited in scope. ${ }^{16}$ Thus, the interruption of inferior alveolar artery supply provoked a localized ischemic response, that was accompanied by a slow repair process of revascularization, reossification, and resorption of necrotic bone. ${ }^{17}$ Each of these previous events have accounted for the altered mandibular morphology seen in the enucleation-extraction procedure.

Absence of teeth, along with the alveolar bone atrophy, consistently reduced the body height in experimental hemimandibles. Compensatory functional mechanisms that, for the most part, involved the masticatory muscles attempted to bring the affected mandibular side back into occlusion, causing the experimental sides to shift medially and cranially. The medial pterygoid muscle appeared to be the primary muscle involved. The decrease in body height, seemingly, was offset in some specimens by an abnormal growth of the alveolar dental processes in the hemimaxillas. Computer analysis revealed these elongations were not significant (Table 2, Fig 2).

As a consequence of the medial movement of the experimental sides, it was expected that a lateral compression of the oral viscera, such as the tongue, and nearby structures and regions, such as the sublingual gland and pharynx, would displace the sham hemimandibles laterally. A slight displacement was produced, as shown by a comparison of the gonion-bulla distance between sham hemimandibles in enucleated series with contralateral sides in control hamsters (Tables 2, 4).

The enucleation procedure was responsible for a significant decrease in the length of the mandible as judged in terms of sample size and probability value. Hamsters 3 weeks old have molars already erupted and incisors that function. Different results 
may have been obtained if younger hamsters were used. ${ }^{18}$

A general analysis obtained in the condylectomy series confirms previous findings by Giannelli and Moorrees ${ }^{18}$ and Sarnat and Engel, ${ }^{19}$ who found that condylectomies do not modify occlusion as judged by normal jaw relationships. The only variable that was altered in this series was the mandibular length, supra-angular notch-infradentale distance. The studies of Enlow, ${ }^{2}$ Enlow and Harris, ${ }^{20}$ and Scott $^{21}$ in humans have shown that the articular cartilage operates as a growth site and is responsible for the upward and backward elongation of the ramus. Based on the assumption that the articular cartilage in the hamster mandible performs a function similar to that of humans, the decrease in length of the experimental hemimandibles would be related directly to the ramus rather than to the mandibular body.

The present statistical study has helped in the evaluation of the effect of the condylectomy and enucleation-extractions. Criteria used were changes in mandibular morphology, loss of normal occlusion, and spatial shifting of the experimental sides. It was found that the enucleation-extraction surgery produced the most pronounced morphologic and functional alteration of the mandible. The three principal factors involved and responsible for these changes were the loss of teeth, alveolar atrophy, and impairment of circulation to the mandibular body because of vascular interruptions linked to the enucleation procedure. Detailed changes in vascular patterns of the mandible still need to be described in detail. Condylectomies, however, did not produce any significant changes in the morphology of the mandibular body that could lead to abnormal occlusion and/or masticatory function.

\section{Conclusions}

Enucleation of the incisor germinal center followed by the extraction of molars in Syrian hamsters was directly associated with several pronounced changes in mandibular morphology. These changes included a decrease in size of the mandibular body, loss of normal occlusion, and a shifting of the mandibular body medially and cranially. These changes may be related to loss of teeth, alveolar bone atrophy, and impaired nutritional circulation because of enucleation procedures. In hamsters with condylectomies, the length of the experimental hemimandibles was reduced routinely because of the loss of the articular cartilage and subsequent impairment of ramal growth. No changes in occlusion and masticatory function were noticed in this series.

\section{References}

1. Sicher, H.: Oral Histology, 4th ed, St. Louis, Mo: C. V. Mosby Co., 1965.

2. ENLow, D.E.: The Human Face, New York: Hoeber Medical Division, Harper and Row Co., 1968, p 134.

3. HARRIS, P.F., and WARD, P.H.: Unilateral Hyperplasia of the Mandibular Condyle, Laryngoscope 78:1475-1486, 1968.

4. Joo, Y.J., and KINNMAN, I.: Ankylosis of the Temporomandibular Joint, Laryngoscope 77:2008-2021, 1967.

5. BROMBERG, B.E.; SONG, I.C.; and RADlauer, C.B.: Surgical Treatment of Massive Bony Ankylosis of the Temporomandibular Joint, Plast Reconst Surg 43:66-70, 1969.

6. ANDERSON, D.E., and MCCLENDON, J.L.: Cherubism-Hereditary Fibrous Dysplasia of the Jaws: I. Genetic Considerations, Oral Surg 15(suppl):5-16, 1926.

7. Schlumeberger, H.G.: Fibrous Dysplasia (Ossifying Fibroma) of the Maxilla and Mandible, Amer J Orth Oral Surg 32:579$587,1946$.

8. Waldron, C.A.: Giant Cell Tumors of the Jaw Bones, Oral Surg 6:1055-1064, 1953.

9. Winter, C.R., and Matocco, P.D.: Osteogenesis Imperfecta and Odontogenesis Imperfecta, Oral Surg 2:782-798, 1949.

10. Pietrokovsi, J., and Massler, M.: Alveolar Ridge Resorption Following Tooth Extraction, J Proth Dent 17:21-27, 1967.

11. Castelli, W.A.: Vascular Architecture of the Human Adult Mandible, $J$ Dent Res 42:786-792, 1963 .

12. Castelli, W.A., and Huelke, D.F.: The Arterial System of the Head and Neck of the Rhesus Monkey with Emphasis on the External Carotid System, Amer $J$ Anat 116:149-170, 1965.

13. Huelke, D.F., and Castelli, W.A.: The Blood Supply of the Rat Mandible, Anat Rec 143:335-343, 1966.

14. Boyd, T.G.; Castelli, W.A.; and Huelke, D.F.: Arterial Supply of the Guinea Pig Mandible, $J$ Dent Res 46:1064-1067, 1967.

15. Converse, J.M.; Uhlschmid, G.K.; and Ballantyne, D.L.: Plasmatic Circulation in Skin Graft-The Phase of Serum Im- 
bibition, Plast Reconst Surg 43:495-499, 1969.

16. Collins, D.H.: The Histological Structure of Bone, $J$ Bone Joint Surg 39B:770-780, 1957.

17. EdeIKeN, J.; HodeS, P.J.; Libshitz, H.I.; and Weller, M.H.: Bone Ischemia, Rad Clin N Amer 5:515-529, 1967.

18. Gianelli, A.A., and Moorrees, C.F.A.: Condylectomy in the Rat, Arch Oral Biol 10:101-106, 1965.
19. Sarnat, B.G., and Engel, M.B.: A Serial Study of Mandibular Growth After the Removal of the Condyle in the Macaca Rhesus Monkey, Plast Reconst Surg 7: 364-380, 1951.

20. ENLow, D.H., and Harris, D.B.: A Study of the Postnatal Growth of the Human Mandible, Amer J Orth 50:25-50, 1964.

21. Scotr, J.H.: The Growth of the Human Face, Proc Roy Soc Med London 47:91100, 1954. 